\title{
Reasons for the Creation of New Social Networks by the Elderly after Relocation
}

\author{
Yoshiko Kudo ${ }^{1,2^{\star}}$, Kazuko Saeki ${ }^{3}$ \\ ${ }^{1}$ Graduate School of Health Sciences' Hokkaido University, Sapporo, Japan; \\ *Corresponding Author: cxm02601@hoku-iryo-u.ac.jp \\ ${ }^{2}$ School of Nursing, Health Sciences University of Hokkaido, Tobetsu-cho, Japan \\ ${ }^{3}$ Hokkaido University, Sapporo, Japan
}

Received 16 September 2013; revised 25 October 2013; accepted 8 November 2013

Copyright (c) 2013 Yoshiko Kudo, Kazuko Saeki. This is an open access article distributed under the Creative Commons Attribution License, which permits unrestricted use, distribution, and reproduction in any medium, provided the original work is properly cited.

\begin{abstract}
It is important for the relocated elderly to create social networks within their new environment for their lives and their health. This research examined the reasons why the relocated elderly create social networks in the neighborhood. The research subject area is one snowfall town in Hokkaido, Japan. The subjects are 20 elderly people, who have been relocated to the town. The public health nurses individually conducted an interview and broke down the verbatim records into qualitative descriptions. The subjects ranged from 68 to 94 years old. Reasons why the elderly create social networks in their neighborhoods are to make their lives easier, to prepare for emergencies, to get rid of their loneliness, and to enjoy their lives. Community health providers should understand the need for neighboring social networks based on the elderly people's condition, and support and create new networks in their community depending on their situations.
\end{abstract}

Keywords: Relocation; Elderly; Neighborhood; Social Network; Risk Management

\section{INTRODUCTION}

The elderly population in Japan surpassed 22 percent (28 million people) and the elderly population is expected to continually increase in the future as well [1]. In Japan, the importance of preventing the elderly from being in need of care in order to maintain the current supply system of the Japanese Association of Healthcare Service is emphasized [2]. At the same time, the relocated elderly population in Japan is increasing, and the percentage of the elderly population aged 65 or above, who have experienced relocation in the past 5 years is approximately 10 percent [3].

The reasons for the relocation of the elderly are retirements, housing and financial conditions, changes in the family structure such as a spouse's death, and changes in health condition [4,5]. In the Sixth National Survey on Migration in Japan (2010), the most common reasons for the relocation of the elderly aged 65 or above for both men and women were "family-related reasons" and "housing-related reasons" [3]. For elderly people, relocation is a significant event, and it became apparent that contributing factors such as whether the relocation is prepared or not, whether the relocation is voluntary or involuntary as well as their health condition and controllability have an impact on their health conditions later on and life expectancies. [6,7].

For the relocated elderly to create social networks in a new environment is considered to be a critical issue. In research regarding accommodation after relocation, the following became clear: social networks can be the mediator for the relocation stress [8], learned resourcefulness-related relocation adjustment [9], and social interaction of the elderly with their environment is decisive for life adjustment [10]. Thus, despite the changes in their environment due to relocation, if there is a restructuring of the social network after the relocation, then it can alleviate the negative impact of being relocated.

In research regarding the factors of the elderly people's QOL and health, it is shown that the neighborhood factors, environmental buoying and social network were linked to their health [11]. For the elderly, it is also reported that communications with their friends rather than their family and relatives could have an impact on the long-term survival rate [12]. Further, it is said that social networks can become a part of the social capital of the elderly people's lives, and it is expected that the research 
on social networks in neighborhoods for the elderly will be carried out in the future as well [13].

It is getting apparent that it is significant for the elderly to create a neighboring social network and to alleviate isolation [13-15]. However, as of now there are few reports why the elderly people create social networks from the viewpoint of the elderly themselves.

The purpose of this research is to examine the reasons why the relocated elderly create social networks in the neighborhood. It is thought that it is important for the relocated elderly to create a neighboring social network for their health and life later on. This time, the research questions are what kind of reasons and what kind of people that the relocated elderly create social networks with.

The significance of the research is to understand the elderly people's feelings toward neighboring social networks after the relocation and help to create support which is considerate to an individual feeling. At the same time, in order to enhance the strength of communities where the elderly live, shedding a light on what kind of people the elderly people were seeking around them and what kind of expectation they had will become materials for considering a community level intervention.

\section{METHODS}

\subsection{Field and Participants}

They are 65 years or above who relocated in the past 5 years to "A town" suburb in the metropolitan areas of Hokkaido. The population of A town is about 20,000 and the aging rate is about 18 percent. The number of the relocated elderly to the town is about 10 to 20 people per year. The approach to recruit the relocated elderly people within 5 years was through a referral by the local welfare commissioners in the town.

Researchers asked the local welfare commissioners association to support to this study as researchers had participated their meeting. All of local welfare commissioners member are 40 people. Six of the local welfare commissioners introduced to researchers the candidates (14 people) who relocated and being appropriate for this research conditions. Another procedure is that researchers directly contacted members of the Health care program provided by the town which aims to prevent the elderly people from staying at home all the time. Participants were whom researchers had met in the health care program. Researchers had participated 10 times and asked them to entry this research. No people rejected in both procedures.

The subject area is a town with heavy snowfall. In winter, the residents need to remove snow off the streets and roofs and a block-association and neighbors mutually cooperate to work it out. There are no large condominiums in the research subject area, and all of the sub- jects live in public one-story houses or detached houses.

\subsection{Data Collection}

The 3 certified public health nurses conducted an individual interview. The semi-structured interviews were conducted individually. Interview took 30 - 120 minutes. The location of each interview was chosen according to their hopes e.g. their house or a room of the health center. The following questions were asked to elderly people. "What kind of change were happened, as you had relocation, with neighborhood between before and after the relocation?", "How did greet in the neighborhood immediately after the relocation?", "Usually, How are you doing with association with the neighbors?"

\subsection{Consideration of Ethical Sensitivity}

Verbal and written explanations of the purpose of the research were given to the all participants. Upon getting consents from them, the interviews were recorded and the verbatim records were written. Researchers kept The Code of Ethics for Nurses [16] strictly in all the procedure. It was also explained to them that personal information would be strictly maintained and the obtained data would not be used other than for the purpose of this research.

\subsection{Data Analysis}

The qualitative inductive way was taken for the method of analysis.

At the first stage of the data analysis, the researchers repeatedly and carefully read the transcripts with the research questions in mind. Next, the comments regarding neighboring social networks from the transcripts were extracted from each case individually. Then, the comments regarding the reasons for making neighboring social networks and the people who they create networks with were extracted, and those contents were compared by the elderly who live alone and those live with their families.

The table of the work of data was made according to the individual. The portion told about the relation with the neighborhood was extracted as a code. The code for all the participants was overlooked. The similar code was arranged in the near and the subcategory was made. When the meaning of a subcategory was similar, a category was completed. In this process, the joint research person analyzed together and one person experienced in qualitative research joined examination. In order to enhance the credibility of the analysis, thorough deliberations were made among the collaborators.

\section{RESULTS}

Table 1 shows participant's characteristics. There were 
Table 1. Characteristics of the participants.

\begin{tabular}{ccc}
\hline & Characteristics & $\mathrm{n}$ \\
\hline Total & Male & 20 \\
Sex & Female & 5 \\
Age & $64-69$ & 15 \\
& $70-79$ & 4 \\
Period after & 80 - 94 & 11 \\
Relocation & -1 year & 5 \\
& 1 - 2 years & 7 \\
Living & 3 - 5 years & 6 \\
Arrangement & Alone & 7 \\
Marriage & Living with family members & 14 \\
& Living with spouse & 8 \\
Physical Function & Bereavement & 10 \\
& Unmarried & 2 \\
& Independent (Healthy) & 13 \\
& Requiring Care or Cure & 7 \\
Trigger of relocation & Recommendation from & \\
& others (Preparation to incidence of & 9 \\
& health problem) & \\
& Bankruptcy & 3 \\
& Buying house & 3 \\
& Eviction & 3 \\
& Seeking cheaper house & 2 \\
\hline & & \\
& & \\
& &
\end{tabular}

20 participants for this study. Their age range was from 68 to 94, and there were 15 females and 5 males. There were 6 elderly who live alone. There were 7 people who require some partial care or cure, and the rest of the people's IADL (life function) was self-sustained. The trigger of their relocation varied such as physical decay, sickness, recommendation from someone, housing factors, financial reasons, and so on.

\subsection{The Kind of People with Whom the Elderly Create Social Networks in the Neighborhood}

Table 2 illustrates the relationships with the people that the elderly creates networks with and the reason why they create networks with each, putting the elderly people who live alone and those who live with their families in separate columns. The kind of people is sorted into 3 groups which are categorized based on the distance from the residence. The 3 groups are in the nearest neighborhood such as next door neighbors and people living nearby, in walking distance such as people that they encountered in walking, shopping, going clinics, neighborhood association members and someone in senior people's club, and in sphere of their daily lives such as health care program participants and staff members, commissioned local welfare volunteers, and longtime old friends.

\subsection{The Reasons why the Elderly Create Social Networks in the Neighborhood}

The categories of the reasons why the elderly create social networks are expressed with the symbol of $<<>>$ and the subcategories are expressed with the symbol of $<$ $>$, below. The reasons why the elderly people create neighborhood social networks are sorted out into 4 categories such as $<<$ to make their lives easier $>>$, $<<$ to prepare for emergencies $>>$, $<<$ to get rid of their lonelyness $>>$, and $<<$ to enjoy their lives $>>$.

\subsection{The Category: To Make Their Lives Easier}

In the category of $<<$ to make their lives easier $>>$, it was pointed out that $<$ to help each other $>$, $<$ to gain living information $>$, $<$ to get familiar with people and an environment $>$, and $<$ to avoid creating animosity $>$. The subcategories of $<$ to help each other $>$ and $<$ to gain living information $>$ are mainly seen for those who live alone. The details of the subcategory $<$ to help each other $>$ are such as talking to someone who lives close, borrowing and lending things between each other, and going out together. In this case, they seemed to take actions not only getting one-sided support but also to consider providing something from them. In the subcategory $<$ to gain living information>, they talk to people that they encounter outside such as shopping stores, doctors offices, and public baths in addition to neighbors, and they gain various information such as directions for stores and public facilities, some store products, and so on.

In the subcategory < to get familiar with people and an environment>, they try to become acquainted with their neighbors. In other words, they create networks in order to adjust to new surroundings and make their lives comfortable. There was a comment, "I can live at ease since I'm getting to know the surrounding people." If they are surrounded by strangers, they are forced to live with a tense feeling. Even though the relationship is not that close, a mere acquaintance relationship can make them feel friendly. Therefore, it leads to actions such as saying hello to someone that they encounter.

For the subcategory <to avoid creating animosity>, male elderly people stressed that reason. For example, an elderly man who lives alone commented, "I do not having relationships with neighbors neither before nor after the relocation. It's not a matter of getting accustomed to it or not. But, I do say hi to immediate neighbors.” Most of them don't even seek constructive relationships with their neighbors. However, those people commonly expressed that they say hi to their neighbors just because they want to avoid to be labeled as a man who lacks in common sense or who doesn't even say hi.

In order $<<$ to make their lives easier $>>$, the elderly 
Table 2. The reasons of creating neighborhood's relationships.

\begin{tabular}{|c|c|c|c|c|c|c|c|}
\hline \multirow{2}{*}{$<<$ Category $>>$ subcategory } & \multirow[b]{2}{*}{ Examples of codes } & \multirow{2}{*}{$\begin{array}{c}\text { Nearest } \\
\text { Next } \\
\text { door } \\
\text { people }\end{array}$} & \multicolumn{2}{|c|}{ In walking distance } & \multicolumn{3}{|c|}{ In sphere of their daily life } \\
\hline & & & $\begin{array}{l}\text { People encountered } \\
\text { in shopping } \\
\text { and clinic etc. }\end{array}$ & $\begin{array}{l}\text { Senior club } \\
\text { members }\end{array}$ & $\begin{array}{l}\text { Participants and } \\
\text { staffs of health } \\
\text { care program }\end{array}$ & $\begin{array}{l}\text { Local } \\
\text { welfare } \\
\text { volunteers }\end{array}$ & $\begin{array}{l}\text { Old } \\
\text { friend }\end{array}$ \\
\hline \multicolumn{8}{|l|}{$<<$ To make their lives easier $>>$} \\
\hline To help each other & $\begin{array}{l}\text { - Borrowing or lending of the tool } \\
\text { of snow removal }\end{array}$ & A & & & A & & \\
\hline To gain living information & $\begin{array}{c}\text {-Asking routes and information } \\
\text { on stores etc. }\end{array}$ & A & A & & & & \\
\hline $\begin{array}{l}\text { To get familiar with people } \\
\text { and environment }\end{array}$ & $\begin{array}{l}\text { - Becoming an acquaintance } \\
\text { • Sharing the talk of the weather }\end{array}$ & A F & & & A F & & \\
\hline To avoid creating animosity & $\begin{array}{c}\text {-Avoid being an irrational human } \\
\text { or a bad rumor }\end{array}$ & A F & & & & & \\
\hline \multicolumn{8}{|l|}{$<<$ To prepare for emergencies $>>$} \\
\hline $\begin{array}{l}\text { To feel secured for reserve } \\
\text { of emergencies }\end{array}$ & $\begin{array}{c}\cdot \text { Confirming of one’s safety } \\
\text { • Stabilizing addressee for emergency } \\
\text { situation }\end{array}$ & A & & & & A & \\
\hline \multicolumn{8}{|l|}{$<<$ To get rid of their loneliness $>>$} \\
\hline $\begin{array}{l}\text { To cope with a sense } \\
\text { of loneliness }\end{array}$ & $\begin{array}{l}\text {-A lighthearted chat } \\
\text { • Calling out to each other }\end{array}$ & A F & A F & & A F & & A F \\
\hline $\begin{array}{l}\text { To fill the needs of } \\
\text { belonging to mates }\end{array}$ & - feeling sadness without the place to go & A & A F & A F & & & \\
\hline \multicolumn{8}{|l|}{$<<$ To enjoy their lives $>>$} \\
\hline $\begin{array}{l}\text { To enjoy conversations } \\
\text { as recreation }\end{array}$ & $\begin{array}{l}\cdot \text { Enjoying conversations } \\
\text { • asking neighbors for tea each other }\end{array}$ & A F & & & & & \\
\hline $\begin{array}{l}\text { To maintain their health } \\
\text { with fun }\end{array}$ & $\begin{array}{c}\text { - Pleasure of conversation is added on } \\
\text { taking a walk }\end{array}$ & $\mathrm{F}$ & & & $\mathrm{F}$ & & \\
\hline To enjoy being with people & - Being friends in the same age groups & & & $\mathrm{F}$ & A & & \\
\hline $\begin{array}{l}\text { To carry out some fun } \\
\text { activities that can't do alone }\end{array}$ & $\begin{array}{l}\text { • Trip, Karaoke, Gateball game } \\
\text { • Leaning and enjoying handicraft }\end{array}$ & & & A F & & & \\
\hline
\end{tabular}

“A” indicate the applied category among elderly who live alone; "F” indicate elderly who live with their families.

people who live alone tend to take the initiative to talk to people and communicate with them, and they try to create networks with various people including neighbors and the people that they run into at shopping stores, doctors offices, public baths, and so on.

\subsection{The Category: To Prepare for Emergencies}

In this category, there are two subcategories, < to solve living issues $>$ and $<$ to feel secure for reserve of emergencies $>$.

The possible emergencies that the elderly people assume are sudden deteriorations of their health conditions and risks of involvement with accidents. At the same time, many of them repeated the phrase of "in case of emergency" since Japan often suffers from natural disasters such as earthquakes and typhoons.

They named commissioned local welfare volunteers as a means $<$ to solve living issues $>$ and $<$ to feel secure for reserve of emergencies>. Commissioned local welfare volunteers are assigned to communities across the country under a system based on the Commissioned Welfare Volunteers Act of Japan. Aiming to create a community of welfare, commissioned welfare volunteers are elected by residents in local communities and officially registered workers to support residents.

One of the male elderly commented, “I'm all alone in the world. I'm used to living alone... A commissioned local welfare volunteer is living across from my place. I can talk to him when something happens. I have a stable emergency contact person. I was anxious before, but I feel more secure now.”

\subsection{The Category: To Get Rid of Their Loneliness}

In this category, there are subcategories such as <to cope with a sense of loneliness $>$ and $<$ to fill the needs of belonging to mates $>$. Several interviewees commented 
on their feelings of loneliness. The feelings include a separation from familiar places and the people along with relocations as well as a frustration from the weakening functions of their body and mind and losing control of daily activities. In context, they tried to make themselves feel better through talking to people in new surroundings in order < to cope with a sense of lonelyness $>$. They talk to people such as someone that they run into while out for a walk, new neighborhood friends, participants and staff members for health care programs. Their conversations are not purposeful ones but rather noncommittal ones such as talking about weathers and pets. Those conversations make them feel better and avoid the situation in that they have nobody to talk to.

For instance, one of them commented, "It's hard when I get older. I feel lonely. I feel very appreciative that I got some friends. I feel better when I talk with them."

In terms of the subcategory <to fill the needs of belonging to mates $>$, there was a comment that they feel lonely without joining the senior people's club. At the same time, they tend to fill the needs of belonging to something by creating an individual relationship with someone that they meet and having someone to talk to and go out with. For example, there was a comment, "I started talking with a woman that we met while taking a dog for a walk. I thought that it helped rid my loneliness. Rather than being bored at home, I want to have some places to go out and have fun.” To belong to local organizations and create relationships, in other words, they regularly and intentionally attend meetings of local organizations such as block associations, New Year's events, and annual general meetings, and they tried to show their own existence after the relocation to the new areas.

\subsection{The Category: To Enjoy Their Lives}

The relocated elderly people tried to create social networks $<<$ to enjoy their lives $>>$, and there are some subcategories such as <to enjoy conversations as a recreation $>$, <to maintain their health with fun $>$, < to go out $>$, $<$ to enjoy being with people $>$, and $<$ to carry out some fun activities that can't do alone $>$.

The subcategory <to enjoy conversations as recreation> contained the elements such as exchanging visits, having tea together, having a relatively long conversation, and eating together with next-door neighbors and longtime friends. In this field of rural areas in Japan, to visit close friends and have a good time while having tea and conversations itself is a recreation. In Japan, there is a term for "friends that they have tea together", and the elderly people tried to create those kinds of relationships.

The subcategory < to maintain their health with fun> includes things such as joining a health care program and enjoying exercise together. Elderly people prefer to have some company, expecting that they can continue to exercise which they can't alone. One of the elderly commented that they enjoy conversations with someone new that they encountered while taking a walk. To enjoy a conversation with someone enabled the elderly people to continue taking a walk which they voluntarily started for their health.

The subcategory < to go out $>$ was brought up by someone who lived with family. Through having a place to go and have fun rather than being bored at home, they go out to enjoy their new life and socialize with people there.

In the subcategory $<$ to enjoy being with people $>$, some women who live with their families commonly emphasized joining the senior people's club and the block associations. Here are some comments for example, "I attend the senior people's club. I expressed that I would pay for the membership fee. At first, I was not sure, but I thought I can make some friends and I would feel lonely if I didn't attend at all. I will attend the block association's new year event and the general meeting for the next month." "I was able to make some friends while having a meal and attending a rice-cake pounding event at the block association. Some young people invited me in a good manner and talked to me. Since they are all nice people, I was able to enjoy and grow accustomed to.” They intended "to periodically meet someone of their age" and "to create opportunities to make more friends" through going to places where people gather, and they went out to have meals and attend a rice-cake pounding event and seasonal events "to enjoy being with people".

In the subcategory < to carry out some fun activities that can't do alone $>$, there were the following comments, "to travel" with some associates among the senior people's club, "to enjoy Karaoke and gate-ball” with new neighborhood friends, "to enjoy learning a handicraft" at health care program. Both of those who live alone and with their families experienced a decline in their physical functions and difficulties to take actions on their own due to insecurity as background factors, and they were able to make their lives rich after the relocation through joining some activities with other people.

For the elderly people who live alone, the associates and the staff members that they meet at health care programs as a part of their daily lives are good friends that they have fun together with. The commissioned local welfare volunteers are someone that they can trust and depend on.

\subsection{The Reasons of Creating Neighborhood's Relations by Living Arrangement}

The major reasons for the elderly people who live alone to create networks are $<<$ to make their lives easier $>><<$ to prepare for emergencies $>>$ and $<<$ to get rid of 
their loneliness >>, and they are trying to build relationships with various kinds of people such as neighbors, commissioned local welfare volunteers, someone that they run into, and so on.

The main reasons for the elderly people who live with their families to create neighborhood social networks are $<<$ to get rid of their loneliness $>>$ and $<<$ to enjoy their lives $>>$. In fact, some elderly people who live with their families felt lonesomeness in the daily life. They are trying to communicate with their neighbors, the people that they meet within walking distance, and the people in the existing organizations such as block associations and senior people's club.

\section{DISCUSSIONS}

\subsection{People That the Elderly Create Social Networks with}

In this research, most of the people that the elderly create social networks with are just a few doors away from their residence or within walking distance at the most. There is a typical term of neighbors in Japanese, "3 houses across one's house and both sides of next doors” which represents one's nearest neighbors, and 2 to 3 houses from the elderly people's house are the cores of their neighboring social networks in this research as well. Besides, there is a saying in Japanese, "Better is a neighbor that is near than a brother far off." Likewise the elderly people regard relationships with neighbors as important matters.

People vary according to the needs. Elderly people create networks mainly with neighbors $<<$ to make their lives easier $>>$ and $<<$ to prepare for emergencies $>>$, and they create networks with various kinds of people that they encounter in addition to neighbors $<<$ to get rid of their loneliness $>><<$ To enjoy their lives $>>$, they create networks with new companies that they meet through organizations such as the senior center rather than neighbors and people that they run into.

At the same time, commissioned local welfare volunteers are brought up $<<$ to prepare for emergencies $>>$. The system with commissioned local welfare volunteers in Japan is based on the Commissioned Welfare Volunteers Act [17]. They are public volunteers that are specified by the area and are responsible for the accessible mutual assistance. They receive training regarding the welfare system, and they are also regularly provided with a follow-up training for enhancing their assistance skills. One of the specified roles of commissioned local welfare volunteers is to confirm the safety of the elderly in their assigned areas. Though there are some differences depending on the areas, in the research subject area, "neighborhood watching" was conducted by utilizing the physical distance accessibility of the residence. From the elderly standpoint, they are always aware of the presence of commissioned local welfare volunteers that they can count on in case of sudden changes in their health conditions and in times of disaster.

Strengthening a better rapport with neighbors can cause a new source of stress called interference. Commissioned welfare volunteers are public advisers who were chosen by the residents, and it is thought that the elderly wanted to create a relationship with them who are moderately both a formal and informal entity.

In Japan, society is aging and the households of the elderly couples and the elderly people who live alone are increasing. Therefore, it is thought that not only commissioned local welfare volunteers but also mutual support among neighbors are still important and will become more important.

\subsection{Reasons Why the Relocated Elderly Create Social Networks}

We made an analysis on what kind of needs prompted the elderly to make relationships in unique circumstances such as relocations. Four categories that became apparent in this research were $<<$ to make their lives easier $>>$, $<<$ to prepare for emergencies $>>$, $<<$ to get rid of their loneliness $>>$, and $<<$ to enjoy their lives $>>$. Glass \& Balfour in The Ecological Model of the Aging (EMA) stated the neighborhood social support as one of the environmental buoying factors for the competencies of the elderly people [18]. The elderly people who are aware that their competencies decline tried to build neighboring social networks in new surroundings to complement their competencies with it.

In the reasons why they create neighboring social networks $<<$ to make their lives easier $>>$ and $<<$ to prepare for emergencies $>>$, they regard the relationship with neighborhood as a safety device and one of living selfmanagements. Porter stated that old women were intending to reduce intrusion risk in unique ways, and nurses should explore intentions to reduce intrusion risk and use that information as a basis for individualized interventions to promote safety [19].

Japan often suffers disasters such as earthquakes and typhoons, and the mutual support among the neighborhood associations and neighbors are strongly emphasized. The research subject area is a heavy snowfall area on top of which Japan is prone to disasters. Basically, the residents are required to remove the snow off the streets and roofs, and the cooperation among neighbors is crucial in that area. While there is some hesitation in the relocated elderly people for getting support from neighbors, the elderly people have been creating the relationship of mutual support by offering what they can do to them. Besides, they attend the neighborhood associations to introduce themselves as newly relocated people, and 
both the elderly people who live alone and live with their families seem to commonly do it as preventative crisis-management. Meeting with the surrounding people through an organization such as a neighborhood association can prevent them from being absent from the mutual support network at times of emergencies.

The reason of $<<$ to get rid of their loneliness $>>$ to create neighboring social networks was seen for not only the elderly people who live alone but also the elderly people who live with their families. Even though they live with their families of their children's generation, they are very busy and the elderly people have to "stay home alone during daytime." The elderly people who live with their families still have a sense of isolation which can't be assuaged by just being with their families. The elderly people seek the neighboring social networks to complement emotional healing functions provided by their families of their children's generation. A sense of isolation contributes to the deterioration of the elderly people's health [20,21], and it is thought that to seek the neighboring social networks on their own is an important coping behavior for maintaining their health.

Social networks $<<$ to enjoy their lives $>>$ encapsulate the significance of preventing the condition required for long term care. In the previous research, decline of the elderly people's physical functions, to become in need for care, is reported to be the least as they have social networks [15]. At the same time, <to enjoy conversations as recreation $>$ encourages to achieve the development tasks in older age. The elderly people recollect their lives through talking with people and they move forward to the integration of life. Senior people often face the psychological crisis such as a sense of loss and isolation, and decline of self-esteem and dignity from retirement and separation from the previous place. However, positive cognitions had a moderating and a partial mediating effect on the relationship between relocation controllability and relocation adjustment [22,23]. It is thought that it is possible to improve one's quality of life through gaining roles in communities and building relationships with people if they create neighboring social networks.

\subsection{Suggestions for Health Care Practices}

We were able to deepen understanding of why the relocated elderly create neighboring social networks from an elderly view and feelings. The outcome of this research can be useful for planning supports in which the elderly people's feelings are considered.

The living arrangements of older persons play a key role in their use and informal care, as well as in their health and well-being [24]. The elderly people who live alone tend to seek building relationships with neighbors as part of control of their lives and crisis management.
The elderly people who live with their families leave an instrumental support up to their families, and they tend to seek neighboring social networks as a means to alleviate a sense of isolation, to enjoy their lives, and to improve their QOL. The 4 reasons why the relocated elderly create networks in this research can be regarded as a part of their expectations for the communal society. In order to create the comfortable and friendly communities to the elderly and relocated people, the community health nurses are required to convey the elderly people's expectations to the local people such as the neighborhood association leaders and commissioned local welfare volunteers. At the same time, it is significant to meet individual needs of the elderly people according to their living arrangement at the actual field of support.

\subsection{Research Limitations}

The subjects in this research are participants of a health care program in one area and the relocated people who were referred by the local welfare commissioner, and they have already met some sort of health care professional. It is thought that the research had limitations because the subjects tended to be relatively in fortunate circumstances among the relocated people.

\section{REFERENCES}

[1] OECD (2011) Help wanted? Providing and paying for long-term care. OECD Publishing, Paris. http://www.oecd.org/els/health-systems/47891458.pdf

[2] Japan Health and Welfare Statistics Association (2009) Vital statistics. Journal of Health and Welfare Statistics, 56, 39-43.

[3] Nishioka, H., Shimizu, M., Chitose, Y., Koike, S. and Kojima, H. (2010) Recent migration trends in Japan: Overview of Results of the sixth national survey on migration 2006. The Japanese Journal of Population, 8, 67-94.

[4] Wiseman, R.F. (1980) Why older people move. Theoretical Issues. Research on Aging, 2, 141-154. http://dx.doi.org/10.1177/016402758022003

[5] Bekhet, A.K., Zauszniewski, J.A. and Nakhla, W.E. (2009) Reasons for relocation to retirement community, a quaritative study. Western Journal of Nursing Research, 31, 462-479. http://dx.doi.org/10.1177/0193945909332009

[6] Schulz, R. and Brenner, G. (1977) Relocation of the aged: A review and theoretical analysis. Journal of Gerontology, 32, 323-333. http://dx.doi.org/10.1093/geronj/32.3.323

[7] Lawton, M.P. (1986) Older people on the move. In: Environment and Aging, Center for the Study of Aging, New York, 135-150.

[8] Eckert, J.K. (1983) Dislocation and relocation of the urban elderly: Social networks as mediators of relocation stress. Human Organization, 42, 39-38.

[9] Bekhet, A.K., Zauszniewski, J.A. and Wykle, M.L. (2008) 
Milieu change and relocation adjustment in elders. Western Journal of Nursing Research, 30, 113-129. http://dx.doi.org/10.1177/0193945907309309

[10] Brand, F.N. and Smith, R.T. (1974) Life adjustment and relocation of the elderly. Journal of Gerontology, 29, 336340. http://dx.doi.org/10.1093/geronj/29.3.336

[11] Glass, T.A. and Balfour, J.L. (2003) Neighborhoods, aging, and functional limitations. In: Kawachi, I. and Berkman, L.F., Eds., Neighborhoods and Health, Oxford University Press, New York, 303-334.

http://dx.doi.org/10.1093/acprof:oso/9780195138382.003 .0014

[12] Giles L.C., Glonek F.V., Luszcz, M.A. and Andrews, R. (2004) Effect of social networks on 10 year survival in very old Australians: the Australian longitudinal study of aging. Journal of Epidemiology \& Community Health, 59, 574-579. http://dx.doi.org/10.1136/jech.2004.025429

[13] Subrarmanian, S.V., Kubzansky, L., Berkman, L., Fay, M. and Kawachi, I. (2006) Neighborhood effects on the selfrated health of elders: Uncovering the relative importance of structural and service-related neighborhood environments. Journal of Gerontology, Social Sciences, 61B, S153-S160.

[14] Thomas, P.A. (2010) Is it better to give or to receive? Social support and the well-being of older adults. Journal of Gerontology, Social sciences, 65B, 351-357.

[15] Tomaka, J., Tompson, S. and Palacios, R. (2006) The relation of social isolation, loneliness, and social support to disease outcome among the elderly. Journal of Aging Health, 18, 359-384. http://dx.doi.org/10.1177/0898264305280993

[16] Japanese Nursing Association. (2003) The code of ethics for nurses.

http://www.nurse.or.jp/jna/english/activities/pdf/ethics200 3.pdf
[17] Aratame, N. (2007) Japan’s Community-oriented welfare for the elderly: Its implications to Asian developing countries aging population in Asia: Experience of Japan, Thailand and China Seminar report on the parallel session at the 8th annual global development conference, China, $1-14$.

[18] Glass, T.A. and Balfour, J.L. (2011) Neighborhoods, aging, and functional limitations. In: Kawachi, I. and Berkman, L.F., Neighborhoods and Health, 1st Edition, Oxford University Press, Oxford, 303-334.

[19] Porter, E.J. and Lasiter, S. (2008) Reducing my risk of intrusion, an intention of old homebound women who live alone. Nursing Research, 57, 351-359. http://dx.doi.org/10.1097/01.NNR.0000313503.30346.e7

[20] House, J.S, Landis, K.R. and Umberson, D. (1988) Social relationships and health. Science, 241, 540-545. http://dx.doi.org/10.1126/science.3399889

[21] Green, B.H., Copeland, J.R.M., Dewey, M.E., Sharma, V., Saunders, P.A., Davidson, I.A., Sullivan, C. and McWilliam, C. (1992) Risk factors for depression in elderly people: A prospective study. Acta Psychiatrica Scandinavica, 86, 213-217. http://dx.doi.org/10.1111/j.1600-0447.1992.tb03254.x

[22] Bekhet, A., Fouad, R. and Zauszniewski, J.A. (2010) The role of positive cognition in Egyptian elders' relocation adjustment, Western Journal of Nursing Research, 32, 115.

[23] Smider, N.A., Essex, M.J. and Ryff, C.D. (1996) Adaptation to community relocation: The interactive influence of psychological resources and contextual factors. Psychology and Aging, 11, 362-372. http://dx.doi.org/10.1037/0882-7974.11.2.362

[24] Hays, J.C. (2002) Living arrangements and health status in later life: A review of recent literature. Public Health Nursing, 19, 136-151. 